\title{
Impact of hydrocarbons transport through pipes on placement areas
}

\author{
Casen Panaitescu ${ }^{*}$, and Maria Stoicescu ${ }^{1}$ \\ ${ }^{1}$ Petroleum-Gas University of Ploiesti, Department of Petroleum Geology and Reservoir Engineering, \\ Bvd. Bucuresti, No.39, Romania
}

\begin{abstract}
Contaminants from the geological environment have induced effects specific to each category of compounds. Complex geological and geochemical studies were based on the geological drilling with depths up to $10 \mathrm{~m}$. The area studied in this paper was the area of Prahova County. The paper aims to present some of the results obtained from analysis performed at soil affected by oil contamination and hydrocarbons products transported through pipelines. The maximum depth from which samples were taken was $10 \mathrm{~m}$. This paper shows the need to investigate each area in terms of pollution.
\end{abstract}

\section{Introduction}

According to [1], organic substances - of natural or artificial origin, represent the main pollutant. Organic substances of natural origin are crude oil, tannin, lignin, carbohydrates, marine biotoxins, etc. Artificial pollutants come from the processing of various substances in refineries (gasoline, diesel, oils, organic solvents, etc.), the organic chemical industry and the petrochemical industry (hydrocarbons, halogenated hydrocarbons, detergents, etc.) [1] Therefore, both crude oil, as a natural organic substance, and the derivatives obtained from its processing, as artificial organic substances, are among the main pollutants of the environment. The presence of crude oil and petroleum products (by large or small leaks) in the environment, more precisely in the soil, could be caused by some technical errors, deliberate human acts, as well as defects in some components of transport systems and storage. Over time, there have been significant oil spills and oil products at global level, which have caused major damage to both the environment and socio-economic activities. At the same time, there are smaller leaks, but with a higher frequency. Their impact depends, among others, on the location, the amount discharged / drained, the type of pollutant, etc. For interpretation the impact that the transport of hydrocarbons through pipelines has on the soil, were realised the complex studies. In this context, the impact of the repairs of hydrocarbon transport pipelines on the environment imposed by the elimination of the effects due to corrosion must also be taken into account. This study was realised from Prahova County, where the transport of hydrocarbons through pipelines has been done for 120 years. In 1901, the first oil transport pipeline was built between Buştenari and CF Băicoi railway station, Prahova County. Therefore, it is obvious that the

\footnotetext{
*Casen Panaitescu: cpanaitescu@upg-ploiesti.ro
} 
historical pollution in Prahova County has reached alarming levels, having a major negative impact on both the environment and human health. It is imperative, to develop studies to analyze the phenomenon of pollution with oil and petroleum products in order to initiate remedial operations and actions to stop or reduce it.

The present paper proposes a study of the contaminated areas by the transport of petroleum products through pipelines, presented in Figure 1. From the obtained results it is observed the existence in the soil of a rather high percentage of pollutant. Due to the properties of existing organic compounds infiltrated into the soil, environmental components soil and water are altered. The results obtained from the study were as follows: THP values in the analyzed soil samples exceed the sensitivity threshold of $200 \mathrm{mg} / \mathrm{kg} \mathrm{d} . \mathrm{m}$ and exceed the alert threshold of $1000 \mathrm{mg} / \mathrm{kg} \mathrm{d.m} \mathrm{;} \mathrm{a} \mathrm{soil} \mathrm{with} \mathrm{a} \mathrm{THP} \mathrm{concentration} \mathrm{greater}$ than $1000 \mathrm{mg} / \mathrm{kg}$ d.m or higher than $0.01 \%$ THP is considered to be contaminated and requires remediation, so that for the analyzed samples it is necessary to perform a treatment for decontamination.

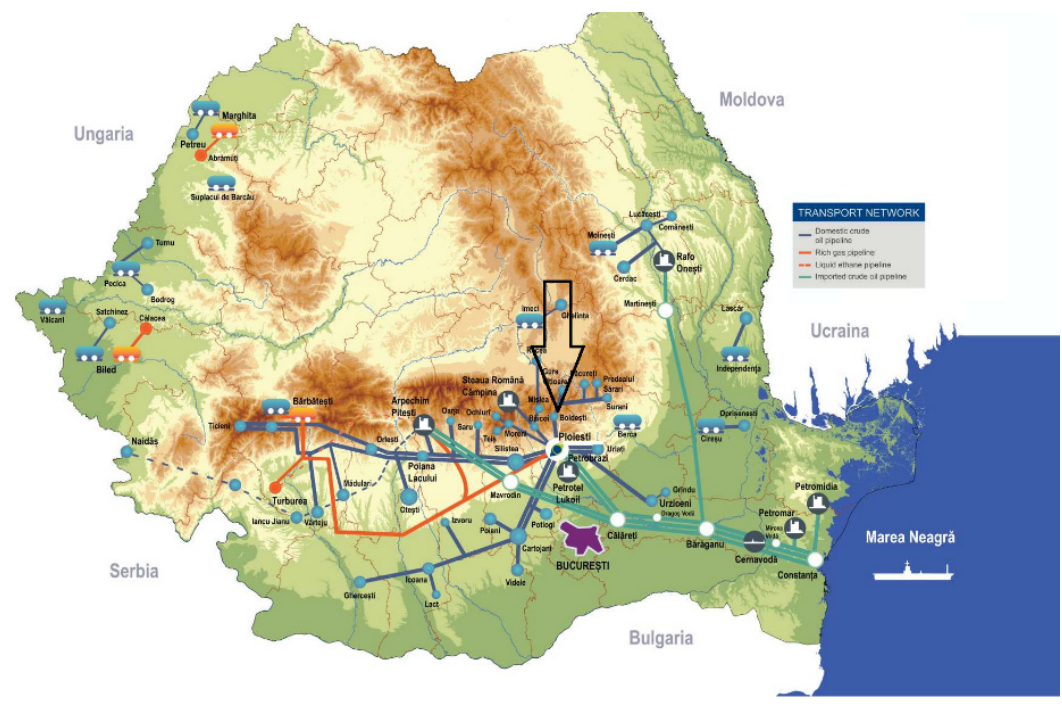

Fig. 1. Location of the sampling points in relation with the existing transportation pipe [2].

When taking the water samples, the presence of the petroleum product was observed in a large proportion for the sample from F $(29 \%)$ and in a smaller proportion in the sample from the drillings $\mathrm{A}, \mathrm{B}, \mathrm{C}$ and $\mathrm{D}$, and much reduced from the samples from the drilling $\mathrm{E}$. The standards in force also require the performance of geoelectric measurements based on the resistivity method, using the Vertical Electrical Sounding (VES) procedure. Thus, higher resistivity values were registered due to the presence of hydrocarbons in the soil. So it was possible to identify areas of predominant accumulation of hydrocarbons in the subsoil. The migration directions of the hydrocarbons respect the flow directions of the aquifer water. An estimated calculation was made of the amount of pollutant existing on the studied site, the total amount of THP resulting being $38 \mathrm{~g} / \mathrm{kg}$. Also, based on the study, proposals were made to rehabilitate the studied area. It can be said that, despite the awareness on the seriousness of this problem, even globally in this area, there is still much to be done to make the fight against pollution more efficient, with lasting effects on long term. A clear understanding of the influence of crude oil / petroleum products contamination on the environment is a global security issue. It is an acute need for all scientists, on one hand, as well as political vectors, on the other hand, to get involved in finding appropriate solutions to save the planet, by focusing on prevention, by applying 
techniques and environmentally friendly technologies in all activities. But it is also a duty for everyone to contribute to slowing down / stopping this phenomenon.

\section{Materials and methods}

The experimental study steps and the equipment used are given in Table 1 .

Table 1. The experimental study steps and the equipment used.

\begin{tabular}{|c|c|c|}
\hline Experimental steps & Equipment & Method \\
\hline Drilling & CHDP 78 Soil Sampling Kit & - \\
\hline Collection point & GPS Stonex S9 GNSS & - \\
\hline Sample & GEO SAMPLER & SR EN ISO 10381-4:2003 \\
\hline
\end{tabular}

After sampling, laboratory analysis were performed for the TPH (Total Petroleum Hydrocarbon) quality indicator. The TPH analysis has been done according to SR ISO 16703: $2011[3,4]$. The results of the values determined for the soil samples taken were compared with the reference values for traces of chemical elements in the soil according to MAPPM Order no. 756/1997 [5] for the approval of the Regulation on the assessment of environmental pollution. Order no. 756/1997 also regulates the sensitive use of land that refers to the maximum accepted level of soil contaminants. In order to avoid the measurement errors, the areas containing gravel and boulders corresponding to a large granulometry were avoided.

In order to have a complete picture of the state of soil contamination, resistivity measurements were made. Soil resistivity was measured with the device Megger DET4TD2 [6]. The basic principle underlying the method is soil homogeneity. The reference is for an average clay of $100 \Omega \mathrm{m}$, for gravels and dry sands an average of $1000 \Omega \mathrm{m}$ and for black soil $40 \Omega \mathrm{m}[6-8]$.

\section{Results and discussion}

Depending on the level of soil sampling, for all six boreholes, the layers were arranged, presented in Table 2.

From a lithological point of view, based on the investigations on the site, the stratification of the land is presented as follows:

- In drilling A:

$\pm 0.00 \mathrm{~m}-1.00 \mathrm{~m}$ a vegetal layer - black;

- 2 .. $4.5 \mathrm{~m}$ a layer of gravel;

$>4.5 \mathrm{~m}$ - a layer of yellow greasy clay;

- In drilling B:

$\pm 0.00 \mathrm{~m}-1.00 \mathrm{~m}$ a vegetal layer - black;

$-2 \ldots 4.2 \mathrm{~m}$ a layer of gravel;

$>4.2 \mathrm{~m}$ - a layer of yellow greasy clay;

- In drilling C:

$\pm 0.00 \mathrm{~m}-1.0 \mathrm{~m}$ a vegetal layer - black;

$-1 \ldots 4.1 \mathrm{~m}$ a layer of gravel;

$>4.1 \mathrm{~m}$ - a layer of yellow greasy clay;

- In drilling D:

$\pm 0.00 \mathrm{~m}$...- $1.0 \mathrm{~m}$ a vegetal layer - black;

-1 ...3.0 $\mathrm{m}$ a layer of gravel;

$>3.00 \mathrm{~m}$ - a layer of yellow greasy clay;

- In drilling E: 
$\pm 0.00 \mathrm{~m}-1.0 \mathrm{~m}$ a vegetal layer - black;

- $1 \ldots 4.7 \mathrm{~m}$ a layer of gravel;

$>4.7 \mathrm{~m}$ - a layer of yellow greasy clay;

- In drilling F:

$\pm 0.00 \mathrm{~m}-1.00 \mathrm{~m}$ a vegetal layer - black;

- 1 .. $4.9 \mathrm{~m}$ a layer of gravel;

$>4.9 \mathrm{~m}$ - a layer of yellow greasy clay.

Table 2. Stratification of soil samples depending on the level of sampling.

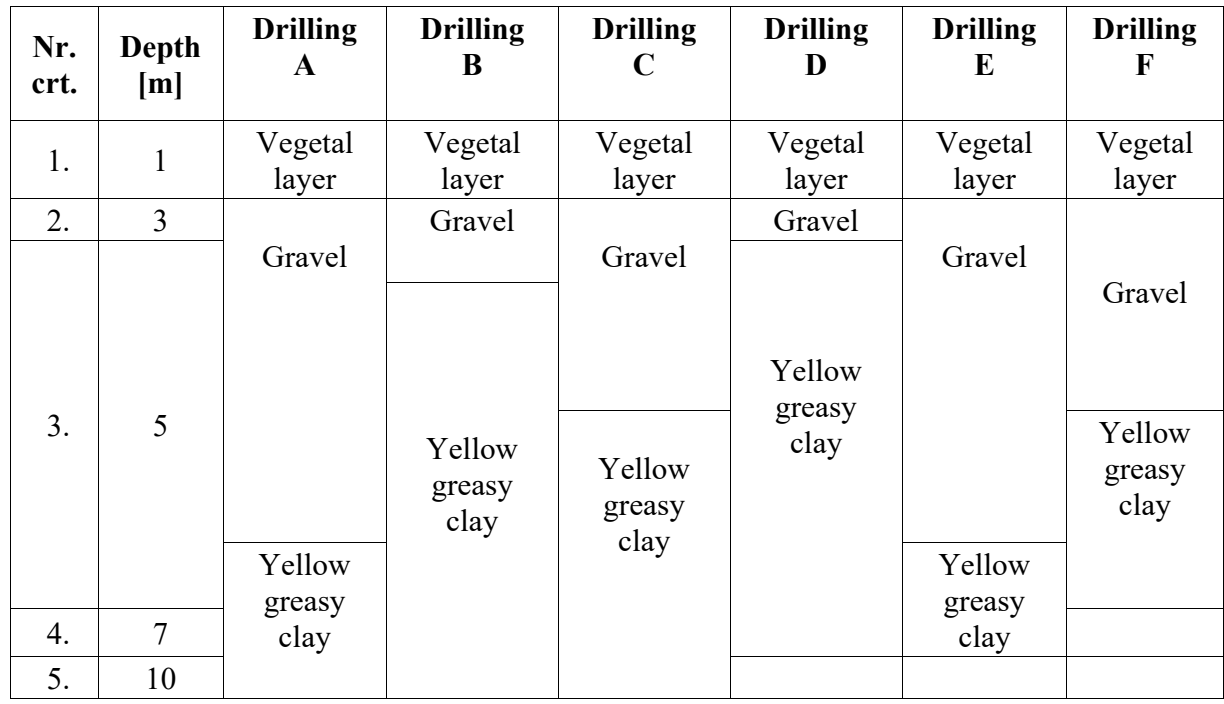

The variations of the oil hydrocarbon concentrations corresponding to the samples taken from the six drills are presented in Figures 2 and 3.

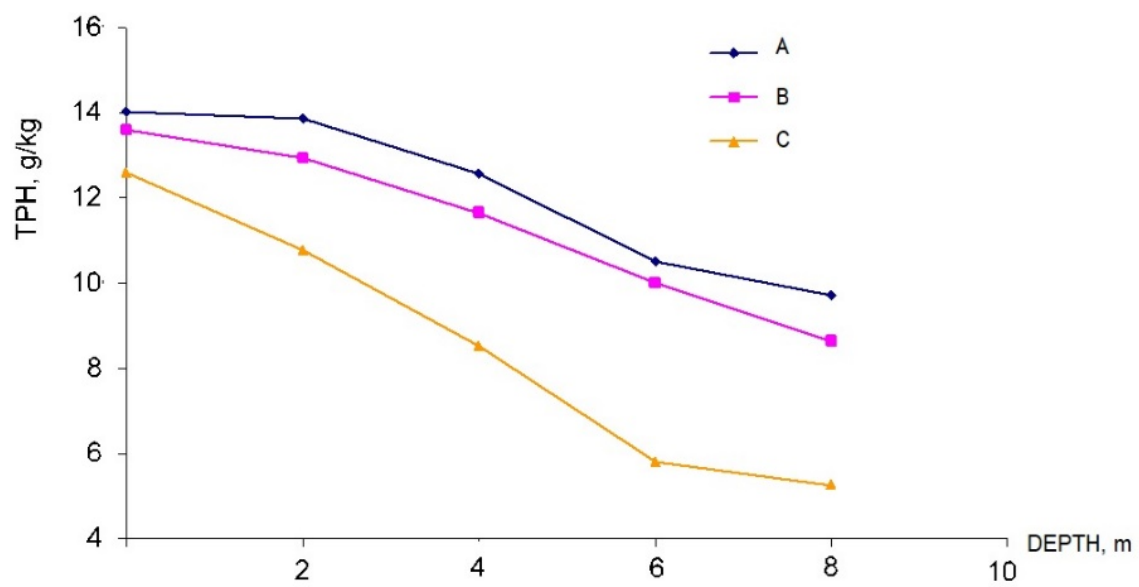

Fig. 2. Variation of hydrocarbon concentration depending on the depth of the drilling A, B and C. 


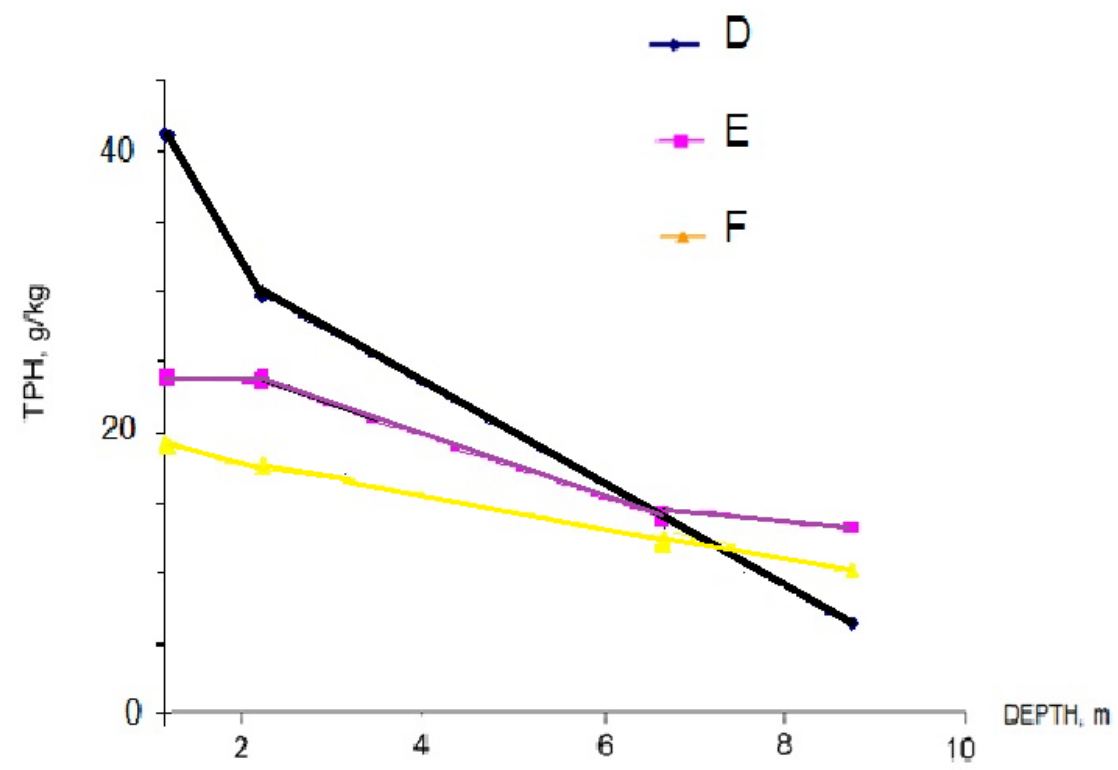

Fig. 3. Variation of hydrocarbon concentration depending on the depth of the drilling D, E and F.

Regarding the degree of contamination of the site, related to the main THP indicator, the following can be concluded:

- In the case of drilling A - at depths of $2 \mathrm{~m}$ and $4 \mathrm{~m}$ it was found that the value of THP indicator concentrations is above the intervention threshold for land with sensitive use. At a depth of $9 \mathrm{~m}$ there is a decrease in the concentration value of this indicator, the result being below the alert threshold.

- In the case of drilling B - at depths $2 \mathrm{~m}$ and $-4 \mathrm{~m}$ it was found that the value of THP indicator concentrations is above the intervention threshold for land with sensitive use. At the depths of $6 \mathrm{~m}$ and $9 \mathrm{~m}$ there is a decrease in the value of the concentrations of this indicator, the results being below the alert threshold.

- In the case of drilling $\mathrm{C}$ - at depths $1 \mathrm{~m}, 6 \mathrm{~m}$ it was found that the value of THP indicator concentrations is above the intervention threshold for land with sensitive use. At a depth of $0.90 \mathrm{~m}$ there is a decrease in the value of the concentration of this indicator, the results being below the alert threshold.

- In the case of drilling D - at depths between $-1 \mathrm{~m}$ and $3 \mathrm{~m}$ it was found that the value of THP indicator concentrations is above the intervention threshold for land with sensitive use. At a depth of $6 \mathrm{~m}$, -a decrease in the value of the concentration of this indicator is found, the results being below the alert threshold.

- In the case of drilling $\mathrm{E}$ - at depths between $2 \mathrm{~m}$ and $8 \mathrm{~m}$ it was found that the value of THP indicator concentrations is above the intervention threshold for land with sensitive use. At a depth of $6 \mathrm{~m}$, there is a decrease in the concentration value of this indicator, the results being above the alert threshold, but below the intervention threshold.

- In the case of drilling F - between $1 \mathrm{~m}$ and $6 \mathrm{~m}$, it was found that the value of the THP indicator concentration is above the alert threshold, but below the intervention threshold for land with sensitive use. 
The data obtained from the resistivity measurements [9] depending on the depth are presented in Table 3.

Table 3. The resistivity measurements depending on the depth.

\begin{tabular}{|c|c|}
\hline Depth, m & Rezistivity, $\Omega \mathrm{m}$ \\
\hline \multicolumn{2}{|c|}{ DRILLING A } \\
\hline 1 & 5214 \\
\hline 3 & 3221 \\
\hline 5 & 2842 \\
\hline 7 & 1514 \\
\hline 10 & 672 \\
\hline \multicolumn{2}{|c|}{ DRILLING B } \\
\hline 1 & 2444 \\
\hline 3 & 3281 \\
\hline 5 & 3640 \\
\hline 7 & 1969 \\
\hline 10 & 1421 \\
\hline \multicolumn{2}{|c|}{ DRILLING C } \\
\hline 1 & 4475 \\
\hline 3 & 3627 \\
\hline 5 & 2871 \\
\hline 7 & 1294 \\
\hline 10 & 962 \\
\hline \multicolumn{2}{|c|}{ DRILLING D } \\
\hline 1 & 5547 \\
\hline 3 & 2894 \\
\hline 5 & 3304 \\
\hline 7 & Inconclusive results \\
\hline 10 & Inconclusive results \\
\hline \multicolumn{2}{|c|}{ DRILLING E } \\
\hline 1 & 4138 \\
\hline 3 & 3868 \\
\hline 5 & 1636 \\
\hline 7 & 1558 \\
\hline 10 & 1036 \\
\hline \multicolumn{2}{|c|}{ DRILLING F } \\
\hline 1 & 4400 \\
\hline 3 & 2498 \\
\hline 5 & 2585 \\
\hline 7 & 2190 \\
\hline 10 & 1873 \\
\hline
\end{tabular}

It is known that resistivity is given by soil mineralogy.

Analyzing the values of resistivity, it is observed that a maximum value, so an intense pollution of the soil with petroleum products, was registered for drilling $\mathrm{D}$, at a depth of 1 $\mathrm{m}$. The minimum values recorded for drilling $\mathrm{A}$ and $\mathrm{C}$ were at a depth of $10 \mathrm{~m}$ This value shows that the volume occupied only by clay has increased, so the contamination is no longer so extensive.

The finding of contamination only in the upper layers led to the further development of bioremediation solutions. The vegetal soil was uncovered according to Figure 4 and then the drilling was performed. The maximum depth up to which the investigations were made was $10 \mathrm{~m}$. 


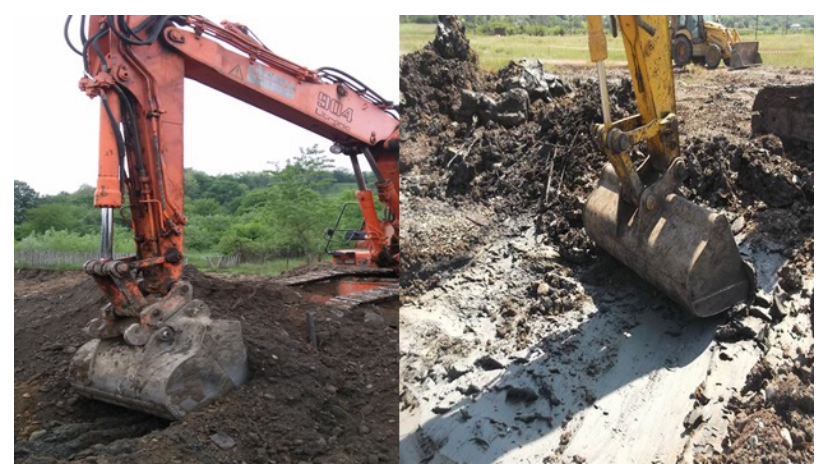

Fig. 4. Excavation of layers contaminated with petroleum products.

\section{Conclusions}

The presence of oil hydrogrounds in the soil leads to major ecological imbalances. Microorganisms providing the amount of nutrients needed are no longer developing and in the long term they die. The determination of TPH value between $380 \mathrm{mg} / \mathrm{kg}$ and $42000 \mathrm{mg} / \mathrm{kg}$ for depths between 1 and $6 \mathrm{~m}$ showed that land use is a sensitive problem. Measuring the resistivity to assess the pollution level of the soil is a commonly accepted solution in environmental practice. Thus, as the depth of the drilling has increased, it has been found that, for the clay soil, at a depth of $10 \mathrm{~m}$, the resistivity value corresponds to an advanced purity and therefore a minimum contamination with petroleum products. All these experimental measurements and determinations have been the basis for future bioremediation solutions, which will help establish the subsequent use. The theoretical and practical models presented in literature can only be applied for similar situations after a detailed analysis of the soil composition and its degree of impurity is carried out. Unfortunately, without these experimental determinations, a decontamination decision cannot be made. Compliance with the legislation in force is a goal that must be the basis for preventing soil pollution and a way to ensure that the working conditions are being followed. If accidental pollution occurs, then on the basis of existing procedures contained in environmental permits and legislation, it is possible to intervene only by knowing at least the basic information about estimating the level of pollution.

\section{References}

1. C. Munteanu, M. Dumitrascu, A. Iliuta, Ecologie si protectia calitatii mediului ( Ed. Balneara, Bucuresti, 2011)

2. Sistemul national de tranport. Available on https://www.conpet.ro/activitatea-conpet/sistemulnational-de-transport/

3. TPH. Available on https://www.atsdr.cdc.gov/toxprofiles/tp123-c2.pdf

4. SR ISO 16703:2011, Soil quality. Determination of content of hydrocarbon in the range $\mathrm{C}_{10}$ to $\mathrm{C}_{40}$ by gas chromatography (2011)

5. Ordinul MAPPM nr. 756/1997 (1997)

6. D. Sarkar, M. Ferguson, R. Datta, S. Birnbaum, Env.Pollution 136 (1), 187-195 (2005)

7. G.D. Todd, R.L. Chessin, J. Colman, Toxicological profile for total petroleum hydrocarbons (TPH), (CRC Press, 1999)

8. H. Nagaraj, M. Munnas, A. Sridharan, Int. J. of Geotech. Eng. 4 (1), 99-110 (2010)

9. Tester pentru masurarea rezistivitatii solului. Available on https://www.arc.ro/det4td2-testerpentru-masurarea-rezistivitatii-solului-cu-patru-tarusi\#tab-2 